\title{
CONCEPT AND REALISATION OF AUTOMATED ROOM CLIMATE CONTROL
}

\author{
D. Jelondz, K. Spasokukotskiy and H.-R. Trankler
}

\author{
Universitgt der Bundeswehr Mьnchen \\ Institut for МеЯ- und Automatisierungstechnik \\ Werner-Heisenberg-Weg 39, D-85577 Neubiberg b. Mьnchen \\ URL: www.unibw-muenchen.de/ima/ and http://smarthome.et.unibw-muenchen.de \\ Email: \{dmitri.zhelondz, konstantyn.spasokukotskiy, ima\}@unibw-muenchen.de
}

\begin{abstract}
: the paper deals with technical problems of automated decentralised indoor climate control in residential buildings. The lead value for the realisation of the control system is the objective thermal comfort. The measurement system to be designed works as a network between a large variety of different sensors and actuators. A comprehensive and flexible EIB networked instrumentation using cheap commercial and prototype sensors and actuators has been created and tested in a realistic test environment. In the paper, the conditions for a modern room climate control are discussed and the technical base for data acquisition system containing several different data collection channels is presented. Extensive measurements with the reliable, fully redundant data acquisition system showed its applicability in residential buildings. Based on the presented concept, different systems configurations can be realised. Following the results, a low-cost decentralised automated room climate control system is able to become a new standard in lowenergy buildings, opening a huge market potential.
\end{abstract}

Keywords: smart home, indoor climate control, energy consumption optimisation, residential building automation.

\section{INTRODUCTION}

Strategies to reduce and optimise energy consumption are a global challenge, both economically and environmentally. The energy consumption in residential buildings consists mainly of two parts: energy required for heating and energy required for driving electrical devices. In recent decades, new construction techniques and insulating materials have been developed which remarkably reduce the heat loss of buildings, enabling high energy savings at the cost of a diminished natural air exchange. In this situation, sufficient indoor air quality must be guaranteed by appropriate heating and ventilation of rooms. Improvements of HVAC systems in residential buildings are aimed at a reduction of energy consumption and an adjustment of comfortable climate in rooms. Decentralised automated thermal climate control in sense of heating and ventilation control separately for each room offer good possibilities to achieve these demands $[1,2]$.

The input parameters for the control system will be obtained from thermal models considering ther- modynamical processes based on the energy balance in the room. The climate response state of rooms is very complex and nonlinear. This implies that the designed climate control system should work as a network between a large variety of different sensors and actuators.

A decentralised measurement and control system has been developed and installed in two test rooms in our SmartHOME Lab which is a singlefamily-type living house recently built on the University Campus site, see Fig. $1^{1}$. The survey has three important goals: the determination of appropriate parameters for the physical room model, the concept for an optimal thermal control separately for each room, and the estimation of the achievable energy savings depending on the user's behaviour.

\section{THERMAL CONDITIONS FOR ROOM CLIMATE CONTROL}

The physical models of thermodynamical processes are based on the energy balance. The simplified energetic balance in a room can be presented as (s. Fig. 2):

${ }^{1}$ Readers are invited to go on a Virtual Tour through our Lab: http://smarthome.et.unibw. muenchen.de 

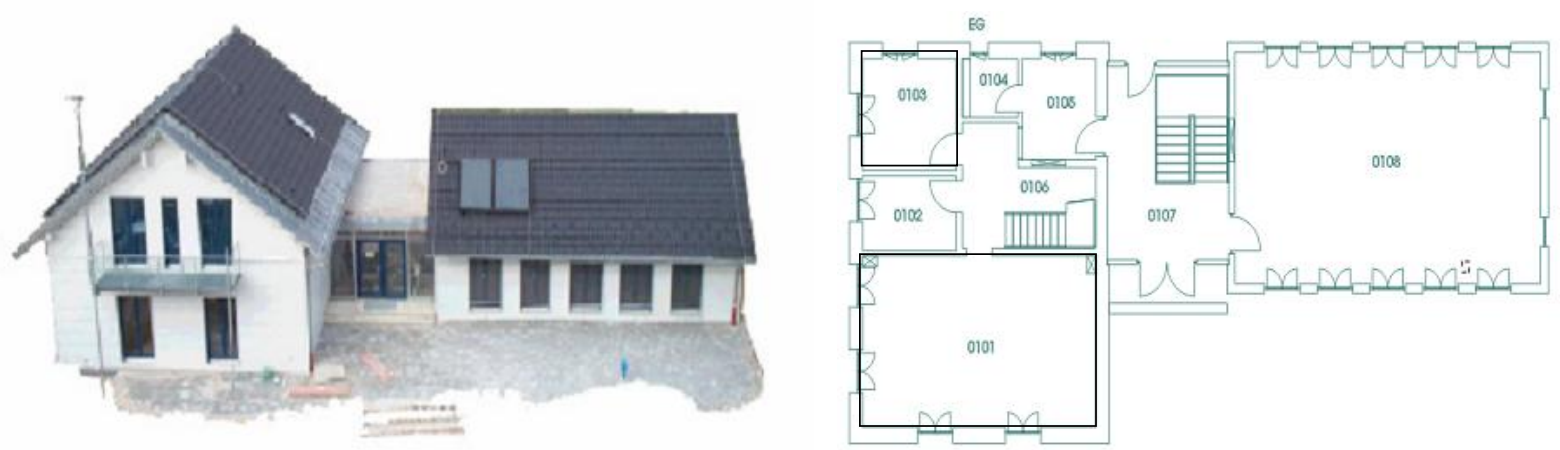

Fig. 1. SmartHOME Lab at Bundeswehr University Munich general view and location of test rooms.

$Q_{H}+Q_{G} \equiv Q_{\text {gain }}=Q_{\text {loss }} \equiv Q_{T}+Q_{L}$

where:

$Q_{H}$ - heat flow to the room from the heating devices,

$Q_{G}$ - heat flow due to heat sources inside the room,

$Q_{T}$ - heat flow due to differences between surface wall temperature and air temperature, lation.

$Q_{L}$ - heat flow due to air exchange from venti-

The heat flow $Q_{G}$ is the summed heat flow of several sources in the room:

$$
Q_{G}=Q_{S}+Q_{P}+Q_{M}+Q_{C}+Q_{B}
$$

where $Q_{S}, Q_{P}, Q_{M}, Q_{C}, Q_{B}$ describe the heat flows due to the solar heating, persons, electrical devices, chemical reactions, and lighting, resp.

The amount of $Q_{H}$ necessary to establish a desired room temperature depends essentially on $Q_{\text {loss }}$ and on the variable disturbance $Q_{G}$. The variations $\Delta Q_{\text {loss }}$ and $\Delta Q_{G}$ should be compensated through $\Delta Q_{H}$.

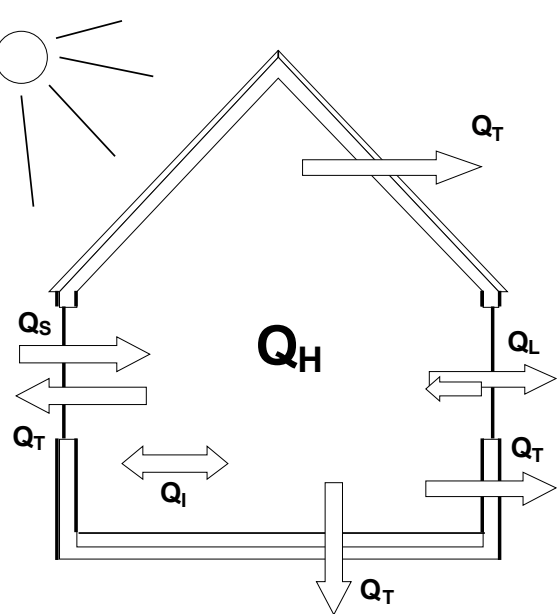

Fig. 2: Thermal balance of rooms [2]
For conventionally constructed buildings the heat loss due to thermal exchanges via the building's envelope is considerably large and $Q_{G}<<Q_{\text {loss }}$ holds. This leads to the following conditions:

$$
Q_{H}>>Q_{G} \Rightarrow \Delta Q_{H}+\Delta Q_{G} \approx \Delta Q_{H}
$$

meaning that a relatively stable physical state can be maintained just by temperature control of any room in the building in accordance to the outdoor air temperature $\left(\Delta Q_{\text {loss }}\right.$ dependence).

In recent times, due to new passive techniques of heat leakage reduction, a large progress in energy saving can be observed (Fig. 2). As a consequence, the following is achieved:

$$
Q_{\text {loss }} \approx Q_{G} \Rightarrow \Delta Q_{H}+\Delta Q_{G} \neq \Delta Q_{H}
$$

According to Eq. (4), the heat flow due to internal heat gains plays a significant role in the thermal balance and can not be ignored. The value $Q_{G}$ depends largely on solar heating gains, i.e. on specific room parameters like location and size of the room and its apertures (windows and doors) as well as on the presence of persons and working electrical devices in the room. If all rooms would be controlled by one central device - as it is conventionally -, at most one room could be controlled optimally, at cost of all other rooms which would be controlled suboptimal meaning a discomfort for the user and a significant waste of energy. As a consequence, an intelligent climate control system should work separately in each room.

1. After German Warmeschutzverordnung, 1995 [3]

2. After German Warmeschutzverordnung, 2000 [4]

3. For low-energy building (research lab) with standard ventilation (bad room climate conditions)

4. For low-energy building with separated smart heating and ventilation as well as use of heat exchangers 


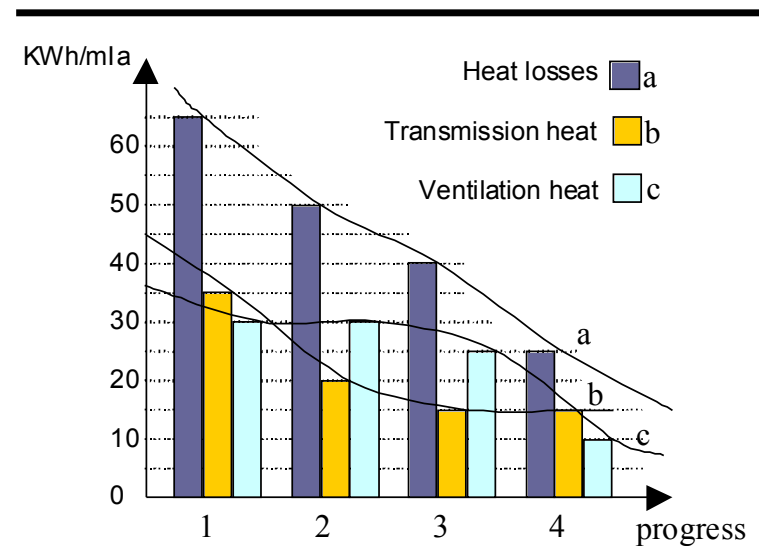

Fig. 3. Energy loss for single family house with ca. $130 m^{2}$ usable area.

Efforts of heat leakage reduction beyond the instructions of the latest Wdrmeschutzverordnung [4] may cause new problems to the thermal comfort in rooms. Because the thermal system is strongly changeable due to disturbances which have much lower setting times than the response time of the room (e.g. the users will open windows and doors frequently), additional heat leakage could even be greater than the savings achieved [2]. This fact can be seen on Fig. 3, where the trends $b$ and $c$ of energy reduction are going to be flat. Estimations of possible energy reductions with sophisticated HVAC systems are shown in the bars 3 and 4 .

\section{CONCEPT FOR A ROOM CLIMATE CONTROL SYSTEM}

Climate control encompasses the research on both the physical processes involved in accomplishing the desired climate in rooms, and on the installations needed to realise the desired climate. A combination is made of theoretical research with simulation support and experiments in which the climate parameters and processes are measured under (semi)practical conditions. Relevant is the dynamic behaviour as well as the spatial distribution of the climate parameters. Here, the control of energy flows (heating, ventilation) is considered in relation to the meteorological values outside and to the specifications of the rooms.

For an analysis of the physical room model, two rooms in the test house with different geometry and location have been selected: a large room (38 $\mathrm{m}^{2}$ ) on the south side ('living room') and a small room $\left(10 \mathrm{~m}^{2}\right)$ on the north side ('home office'), see Fig. 1. Also the heating and ventilation systems in these rooms differ: The 'home office' is heated (and cooled) by a radiator or a under-floor convector and cooled by a decentralised ventilation system. The 'living room' is additionally connected to the central ventilation system and equipped with wall-panel heaters additional to radiators and under-floor convectors.

Out of the large number of different physical parameters influencing the subjective perception of thermal comfort $[5,6]$, the following parameters are considered for continuous registration:

- Mean air room temperature,

- Relative air humidity,

- Mean air velocity,

- Concentration of the carbon dioxide $\left(\mathrm{CO}_{2}\right)$,

- Radiation temperature.

The central ventilation and all detached ventilators and heating devices are centrally controlled. Furthermore, the opening of windows and doors is monitored by reed contacts. Internal heat sources like the presence and the activity of persons in rooms, the warm water usage and the energy consumption of electrical devices (with 'intelligent' wall sockets [7]) will be registered. On behalf of the output of occupancy sensors the temperature set point of the heating system might be reduced or switched off while the room is unoccupied.

The weather data are of great importance for the calculation of the heat flow balance. From a weather station installed on the roof of the test house and connected to the control system via EIB, the following weather parameters are obtained:

- Air temperature,

- Air relative humidity,

- Wind speed,

- Wind direction,

- Sun radiation (global and diffuse),

- Rainfall.

On a total, as much as 36 different parameters are being measured continuously in the room. The specifications of the applied sensors as well as the data flow to the central processing unit are summarised in Table 1.

\section{REALIZATION OF THE TECHNICAL INFRASTRUCTURE}

The consumption of heating energy will be measured both for every heater in the test rooms and for all heating circles in the building. The room temperatures and the valve position will be adjusted and protocolled via EIB. The instrumentation and data flow structure for registering the heat flow from all heaters and heat circles used in the test rooms are shown in Fig. 4. For this purpose, EIB based heat flow meters have been designed. The sensor data are transferred via European Installation Bus (EIB) to the processing unit. 


\begin{tabular}{|c|c|c|c|c|c|c|c|c|}
\hline \multicolumn{9}{|c|}{ Sensors in the test rooms: } \\
\hline Air humidity & 2 & $\begin{array}{l}\text { Inflow, } \\
\text { outflow }\end{array}$ & $\begin{array}{l}\text { Panametrics } \\
\text { MiniCap }\end{array}$ & $5 . .95 \%$ & $1 \%$ & $1.5 \% \mathrm{rF}$ & Voltage & $\begin{array}{l}\mathrm{MCM} \rightarrow \\
\mathrm{EIB} \rightarrow \mathrm{PC}\end{array}$ \\
\hline $\begin{array}{l}\text { Wall surface } \\
\text { temperature }\end{array}$ & $\begin{array}{l}\text { var., } \\
\sim 200\end{array}$ & $0.5 \mathrm{~m}$ grid & $\begin{array}{c}\text { Dallas } \\
\text { DS1820B }\end{array}$ & $-55 . .120^{\circ} \mathrm{C}$ & $0.0625 \mathrm{~K}$ & $0.5 \mathrm{~K}$ & $\begin{array}{l}\text { 1-Wire } \\
\text { bus }^{\mathrm{TM}}\end{array}$ & $\begin{array}{l}\text { 1-Wire } \rightarrow \\
\text { PC }\end{array}$ \\
\hline \multirow{2}{*}{$\begin{array}{l}\text { Heater surface } \\
\text { temperature }\end{array}$} & $2 \mathrm{xHK}$ & $\begin{array}{c}\text { Heater } \\
\text { Inflow and } \\
\text { outflow }\end{array}$ & $\begin{array}{c}\text { Dallas } \\
\text { DS1820B }\end{array}$ & $-55 . .120^{\circ} \mathrm{C}$ & $0.062 \mathrm{~K}$ & $0.5 \mathrm{~K}$ & $\begin{array}{l}\text { 1-Wire } \\
\text { bus }^{\mathrm{TM}}\end{array}$ & $\begin{array}{c}\text { 1-Wire } \rightarrow \\
\text { PC }\end{array}$ \\
\hline & $1 \mathrm{xHK}$ & $\begin{array}{c}\text { Centre of } \\
\text { heater } \\
\text { surface }\end{array}$ & $\begin{array}{c}\text { Dallas } \\
\text { DS1820B }\end{array}$ & $-55 . .120^{\circ} \mathrm{C}$ & $0.0625 \mathrm{~K}$ & $0.5 \mathrm{~K}$ & $\begin{array}{l}\text { 1-Wire } \\
\text { bus }^{\mathrm{TM}}\end{array}$ & $\begin{array}{c}\text { 1-Wire } \rightarrow \\
\text { PC }\end{array}$ \\
\hline $\begin{array}{c}\mathrm{CO}_{2} \\
\text { concentration }\end{array}$ & 1 & Outflow & $\begin{array}{c}\text { Sensor devices } \\
\text { ATQ32 }\end{array}$ & $0 . .5000 \mathrm{ppm}$ & $2 \mathrm{ppm}$ & $\begin{array}{l}1.5 \% \mathrm{v} . \\
\mathrm{MV}\end{array}$ & Voltage & $\begin{array}{l}\mathrm{MCM} \rightarrow \\
\mathrm{EIB} \rightarrow \mathrm{PC}\end{array}$ \\
\hline \multicolumn{9}{|l|}{ Weather station: } \\
\hline Temperature & 1 & Roof & $\begin{array}{c}\text { Thies } \\
1.1005 .54 .161\end{array}$ & $-30 . .70^{\circ} \mathrm{C}$ & $0.1 \mathrm{~K}$ & $0.3 \mathrm{~K}$ & Voltage & $\mathrm{EIB} \rightarrow \mathrm{PC}$ \\
\hline Humidity & 1 & Roof & $\begin{array}{c}\text { Thies } \\
1.1005 .54 .161\end{array}$ & $0 . .100 \%$ & $0.1 \%$ & $2 \% \mathrm{rF}$. & Voltage & $\mathrm{EIB} \rightarrow \mathrm{PC}$ \\
\hline Brightness & 1 & Roof & $\begin{array}{c}\text { Thies } \\
7.1414 .50 .000 \\
\end{array}$ & $\begin{array}{c}0 . .100000 \\
\operatorname{Lux}\end{array}$ & 100 Lux & $\begin{array}{c}5000 \\
\text { Lux } \\
\end{array}$ & Voltage & $\mathrm{EIB} \rightarrow \mathrm{PC}$ \\
\hline Wind direction & 1 & Roof & $\begin{array}{c}\text { Thies } \\
4.3125 .32 .060\end{array}$ & $0 . .360^{\circ}$ & $0.4^{\circ}$ & $2.5^{\circ}$ & Voltage & $\mathrm{EIB} \rightarrow \mathrm{PC}$ \\
\hline Wind velocity & 1 & Roof & $\begin{array}{c}\text { Thies } \\
4.3519 .00 .073\end{array}$ & $0.5 . .50 \mathrm{~m} / \mathrm{s}$ & $0.1 \mathrm{~m} / \mathrm{s}$ & $\begin{array}{c}3 \% \\
\text { of } \mathrm{MV}\end{array}$ & Voltage & $\mathrm{EIB} \rightarrow \mathrm{PC}$ \\
\hline
\end{tabular}

Table 1: Instrumentation in the test rooms and for the weather station. (MV-measured value, HK-heater, MCM-Multi-Chip-Modul, PC-Personal Computer)

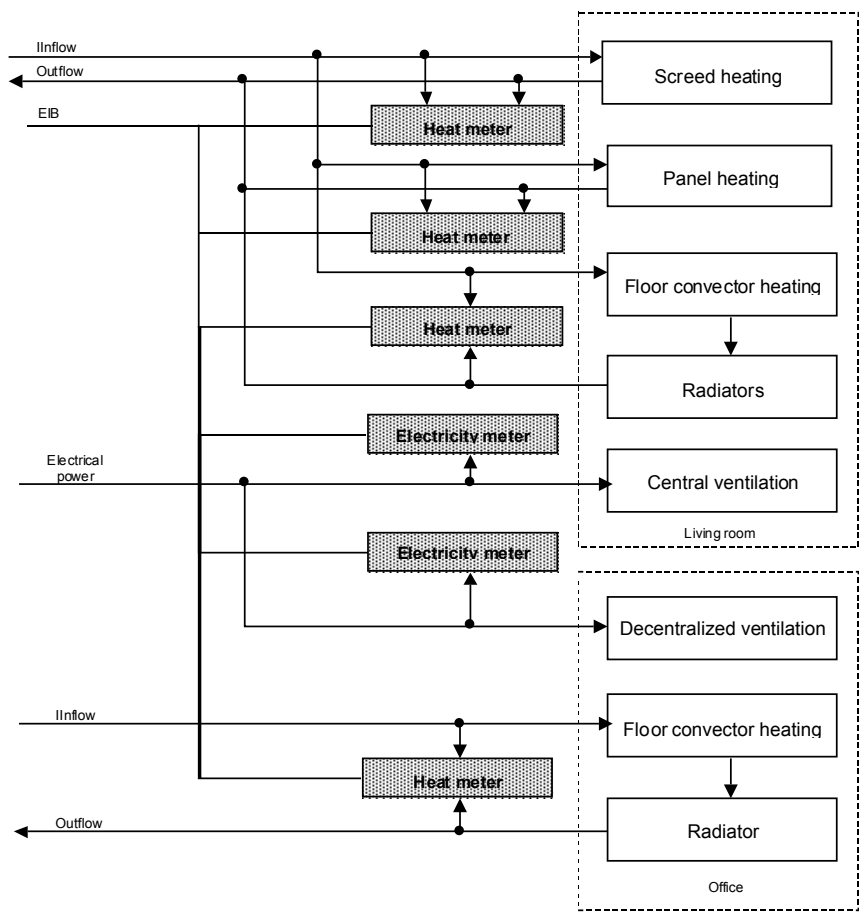

Fig. 4: Heat flow measurement from heaters. Instrum entation and data flow structure

For later marketing requirements, all instrumentation should be installed such that they can be hidden either in the building envelope or in standard technical room equipment. The sensors measuring the indoor air quality [8] have been mounted in the inlet and outlet pipes of the ventilation system (see Fig. 5). The following parameters are measured: air temperature, air humidity, air flow rate, $\mathrm{CO}_{2}$ concentration.

To measure the temperature distribution of the room walls, about 200 temperature sensors (Dallas Semiconductors DS18B20) have been installed in the office on an area of 50 $\mathrm{m}^{2}$. The sensors are integrated into a network with unique 1 -Wire ${ }^{\mathrm{TM}}$ interface.

The sensor data acquisition and processing system consists of two data loggers for reading the data from sensors, a control computer, where the data is processed, and a backup computer for storing the measured data in a database. Both loggers are based on Linux operational system. For reliability reasons, at the same time only one of the loggers acquires the sensor data while the second observes the first. If the first logger fails, the second undertakes its functions (parallel redundancy principle). All the computers are connected to the local network with Internet access (Fig. 6).

The sensors, which are connected to the 3 field buses, are scanned by the data logger with defined time intervals (at present, every $5 \mathrm{~min}$ ). The measurement data is saved in ASCII format on hard disk and transferred via FTP protocol to the data- 


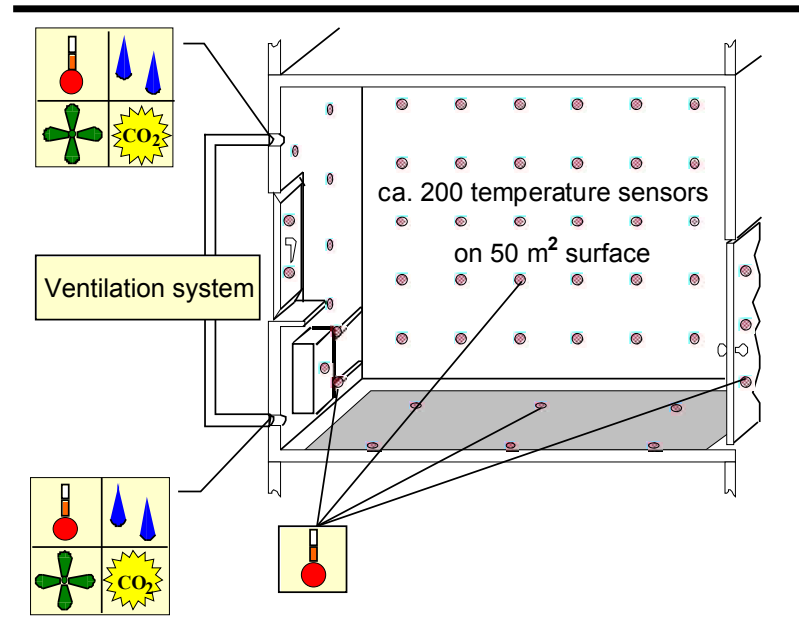

Fig. 5. Test bed for research purposes: Sensor placement in the 'home office

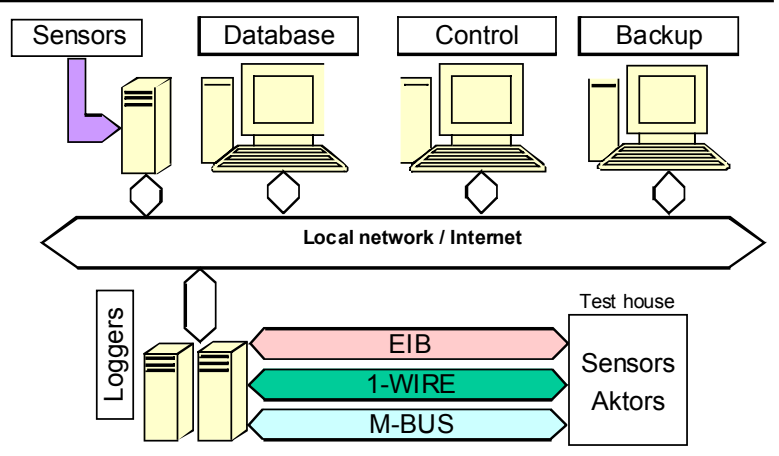

Fig. 6. Data acquisition system

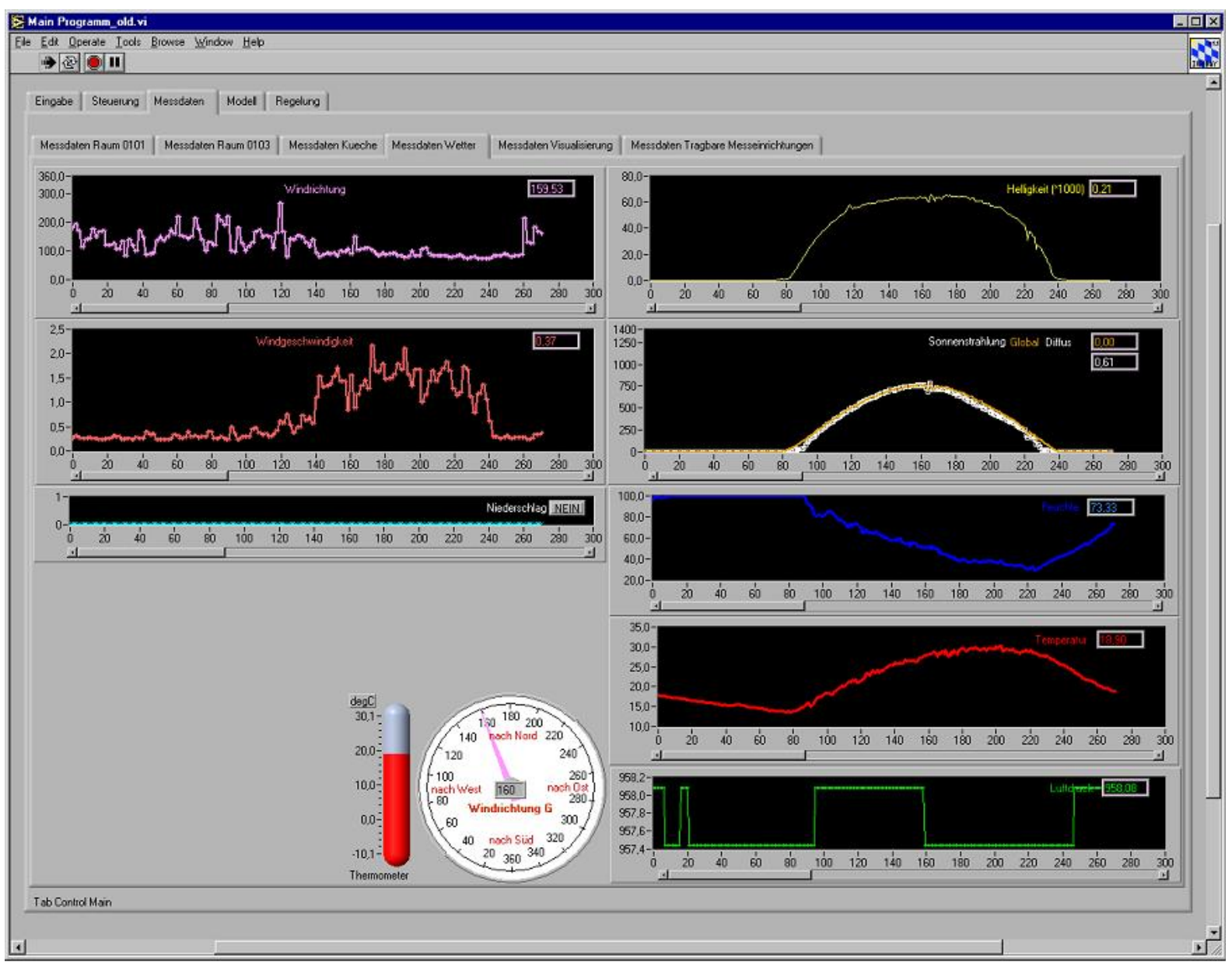

Fig. 7. Visualisation of measurem ent data (screenshot from Control PC). Weather data over a full day: from top to bottom: (left) wind direction, wind speed, rainfall; (right) brightness, sun radiation, humidity, temperature, air pressure

base computer which decodes the data and writes it into the main database (MySQL). Later, the data from the database will be used by the Control PCs for visualisation (see screenshot Fig. 7) and future processing, e.g. to refine the physical room model. The results from the physical room model are used by the control block to produce commands for the actors (e.g. heater valve). The command file is transferred first to the main database and at the appropriate time point via FTP protocol to the data logger, which sends decoded commands via EIB to the actuators. In the described system more than one control computer can be used. The main database is saved daily by the backup computer. 


\section{DISCUSSION}

Energy loss estimations in residential buildings show that automated room climate control systems working separately for each room is likely to become a new standard in low-energy buildings. The lead task for the realisation of the control system is the establishment of an objective thermal comfort. Besides that, automated room climate control is meant to reduce the over-all energy consumption in 'Smart Homes'. In order to obtain parameters for the control system, appropriate thermal room models have to be used. In the paper, a new concept of the technical base of a comprehensive measurement environment has been presented. Based on the well-established EIB technology, a flexible information network for distributed sensors and actuators has been created. On its base, different system configurations for separated room climate automatic control can be realised. Extensive experiments with the reliable full redundant data acquisition system show the applicability of the system in private homes.

Acknowledgement

This work is part of project BA547 (Intelligent Instrumentation of Homes, IWO-BAY) sponsored by Bayerische Forschungsstiftung.

\section{REFERENCES}

[1] C.N.Herrick, K.Connolly: Electrical Control Systems for Heating and Air Conditioning, Englewood Cliffs, Prentice Hall, 1998

[2] Eickenhorst, H.; Joos, L; et al.: Energieeinsparung in Gebduden - Stand der Technik, Entwicklungstendenzen. Vulkan Verlag, Essen, 1998

[3] Verordnung bber einen energiesparenden Wdrmeschutz bei Gebduden (Wdrmeschutzverordnung), August 1994

[4] Verordnung bber einen energiesparenden Wdrmeschutz bei Gebduden (Wdrmeschutzverordnung), Draft February 2000

[5] Moderate thermal environments - Determination of the PMV and PPD indices and specification of the conditions for thermal comfort, ISO Standard 7730-1994

[6] Thermal comfort. ASHRAE Handbook Fundamentals, 1997

[7] W.Mbller, F.Schneider: Surveillance of household appliances using the EIB, EIB Conference, Munich 1998

[8] H.-R.Trdnkler, L.Schratt: Key sensor module for home automation, EIB Conference, Munich 1998 